\title{
New challenges in radiobiology research with microbeams
}

\author{
Marco Durante $\cdot$ Anna A. Friedl
}

Received: 23 May 2011/Accepted: 25 May 2011/Published online: 12 June 2011

(C) Springer-Verlag 2011

\begin{abstract}
There is a continuing interest in the use of microbeam systems designed to deliver ionizing radiation (both photons and particles) with a resolution of a few micrometers or less in biological targets. With more than 30 facilities currently in operation, several new research topics can be explored. In the 9th International Microbeam Workshop held in Darmstadt, Germany, in July 2010, several new ideas and results have been presented, indicating that microbeams will be increasingly important in radiobiology. Subnuclear targeting of single cells for DNA repair studies and microirradiation of 3D or small animal models are among the most promising new research perspectives.
\end{abstract}

Keywords Microbeam · Damage response .

Tissue model

\section{Introduction}

Microbeams were originally designed to overcome the problem of the Poisson distribution of traversals in radiobiology cellular experiments. Obviously, if a given dose of

M. Durante

Biophysics Department, GSI Helmholtz Center for Heavy Ion Research, Planckstraße 1, 64291 Darmstadt, Germany

M. Durante

Institute of Condensed Matter Physics, Darmstadt University

of Technology, Hochschulstraße 3, 64289 Darmstadt, Germany

A. A. Friedl $(\square)$

Department of Radiotherapy and Radiooncology,

University of Munich, Munich, Germany

e-mail: RadiatEnvironBiophys@1rz.uni-muenchen.de charged particles is delivered to a cell population, the number of traversals will not be the same, and consequently, the dose will vary from cell to cell. The problem is particularly serious for high-LET ions, such as $\alpha$-particles and heavy ions, where at low doses the fraction of cells receiving no traversals at all can be very high. The effectiveness of single particle traversals is one of the main issues of radiation protection both on Earth (Brenner and Sachs 2003) and in space (Durante 2009).

The possibility of targeting single cells with a predefined number of particles motivated the construction of the first microbeams in the last decade of the past century (reviewed in Gerardi 2009). This soon made possible the direct study of effects of single traversals through the cell nucleus (Miller et al. 1999) or cytoplasm (Wu et al. 1999) and evidence for the bystander effect (Zhou et al. 2000). However, several other applications were soon introduced and technologies rapidly improved. With the introduction of soft X-ray microbeams (Folkard et al. 2001), it became possible to compare low- and high-LET radiation and to improve the subcellular resolution. Some of these new topics and their current status are summarized below.

\section{DNA damage}

Use of microbeams to visualize recruitment of proteins involved in damage detection, signaling, and repair began early after the turn of the century (Tartier et al. 2003). Hauptner et al. (2004) introduced use of geometric irradiation patterns and demonstrated that the pattern of emerging protein foci reflects the irradiation pattern. Irradiation in geometric patterns also allowed the analysis of the effects of sequential ion microirradiation and the detection of the competition effect, which highlights the 


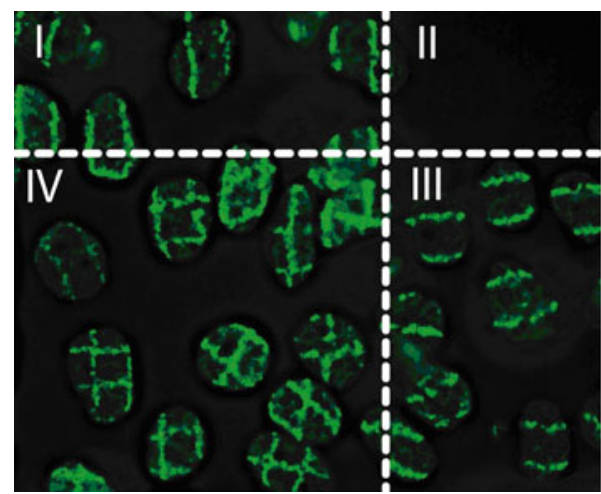

Fig. 1 Competition effect revealed by sequential irradiation with single oxygen ions delivered in line-wise patterns at the Munich microbeam SNAKE. Hela cell monolayer was first irradiated in horizontal line pattern and after $45 \mathrm{~min}$ re-irradiated in vertical line pattern. Immunofluorescence detection of gamma-H2AX (green) reflects the irradiation pattern (first irradiation only in quadrant III,

turnover and binding characteristics of the different DNA repair molecules (Greubel et al. 2008, Fig. 1).

Visualization of DNA damage in subnuclear targets was demonstrated initially at GSI (Heiss et al. 2006) and is today one of the main research topics. Moreover, the subnuclear targeting with heavy ions makes possible to study heterochromatic and euchromatic compartments directly (Jakob et al. 2011, Fig. 2).

The possibility of live cell imaging on the microbeam line will further enhance these possibilities (Hable et al. 2009). For example, the kinetics of recruitment of different proteins can be investigated in individual cells and compared (Mosconi et al. 2011). The DNA damage/repair studies will certainly in future represent one of the main

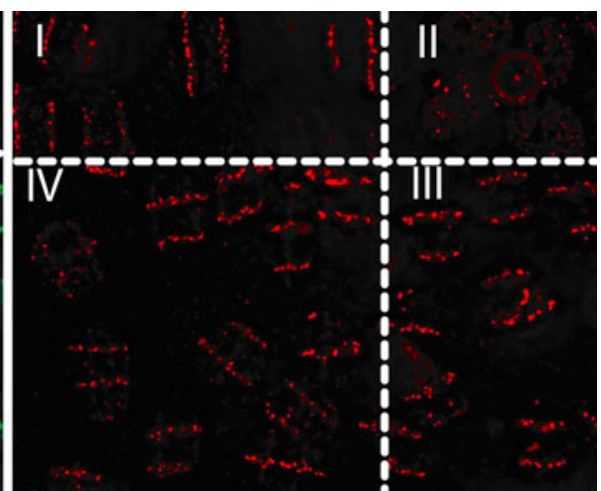

second irradiation only in quadrant $I$, both irradiations in quadrant $I V$, no irradiation in quadrant $I I)$. In contrast, in cells irradiated twice, 53BP1 foci (red) develop only at damage sites induced during the first irradiation, but not in response to the second irradiation (see quadrant $I V)$, while they develop readily in cells that received only the second irradiation (see quadrant I). From (Greubel et al. 2008); modified

focuses of the microbeams with several different options. Given that the vast majority of data on kinetics and mutual dependence of protein recruitment to damage sites gathered so far has been obtained using laser microirradiation (Bekker-Jensen and Mailand 2010), it will be particularly important to systematically investigate whether the data obtained after laser irradiation hold after ionizing irradiation.

\section{Tissue and animal models}

The studies of bystander effect have dominated for many years the applications of microbeams (e.g. Zhou et al.

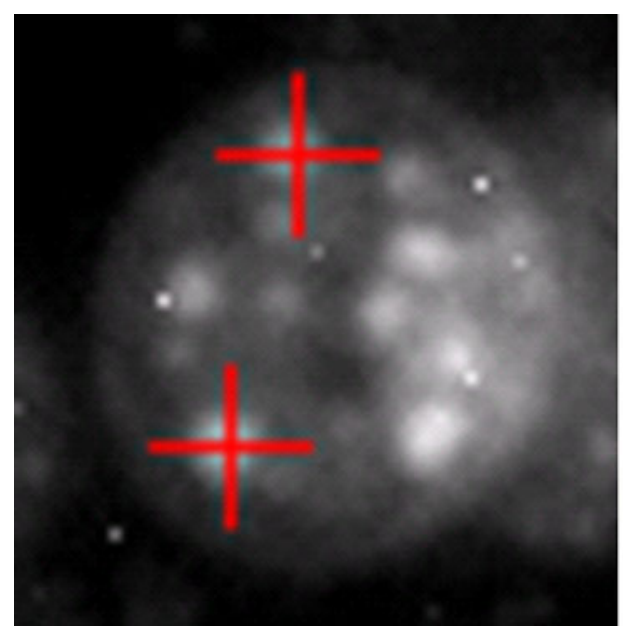

Fig. 2 Microbeam irradiation of subnuclear (hetereochromatic) compartments in mouse embryo fibroblasts (MEF) with heavy ions at the GSI microbeam. The left image shows the aimed targeting of chromocenters (red crosses) for single ion irradiation using Hoechst 33342 (gray scale) as a marker in nuclei of living MEF cells. The

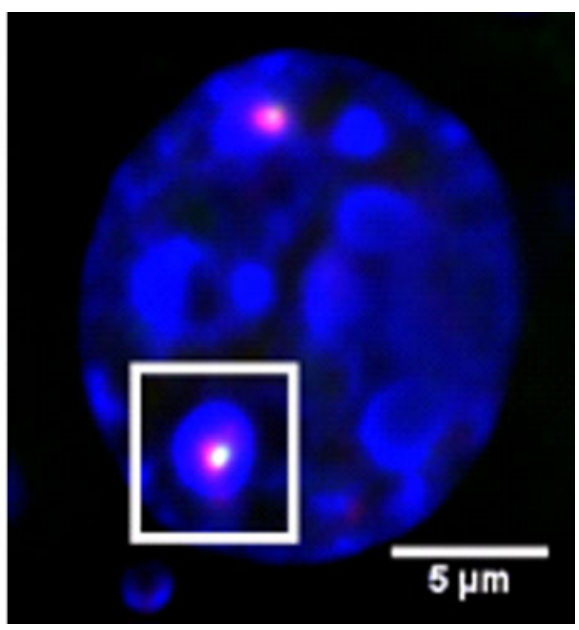

right-hand image shows the same nucleus after fixation at 5 min postirradiation. DNA damage-induced foci of the repair factor XRCC1 (green) and $\mathrm{gH} 2 \mathrm{AX}(\mathrm{red})$ are clearly visualized at the sites of ion traversal. Both proteins co-localize within each of the targeted chromocenters (blue: DAPI DNA staining). From (Jakob et al. 2011) 
2000; Prise et al. 2005). However, experiments with cell monolayers are limited and do not take into account the complex tissue responses. Three-dimensional models can reproduce many of the tissue characteristics in vivo (Griffith and Swartz 2006) and are therefore ideal targets in microbeams for studying non-targeted effects. So far, mostly skin constructs have been used at microbeams (Belyakov et al. 2005; Sedelnikova et al. 2007; Schmid et al. 2010; Miller et al. 2011), but new organotypic slice culture methods offer the possibility of irradiating parts from all kinds of human tissues and to study their late response (Merz et al. 2010). The tissue models at microbeams can be very useful to clarify the role of cell signaling and tissue remodeling in radiation response.

Although traditionally hampered by the limited range of particles and photons used at microbeams, animal models are now also used. So far, these studies focused on very small animals, such as silkworms (Fukamoto et al. 2007) and nematodes (Bertucci et al. 2009), but can provide important insights on long-range non-targeted effects, beyond the possibility of 3D tissue targets.

\section{Generation of ultra-high dose rates}

A rather recent application of microbeams is to produce very short pulses (a few Gy in $\sim 1 \mathrm{~ns}$ ), similar to the conditions expected to occur in particle irradiation setups with laser-driven accelerators (Dollinger et al. 2009). Studies on radiobiological effects of ultra-high dose rates are a prerequisite for potential future applications of laserdriven particle acceleration in radiotherapy (Schmid et al. 2009, 2011). Recently, it was shown that irradiation of mouse tumor models at microbeams can be useful in preparing this new therapy modality (Greubel et al. 2011).

\section{Conclusions}

Microbeams started operations about 30 years ago and have decisively contributed to fundamental new discoveries in radiobiology. The microbeam community is now rapidly expanding and so are the research topics and ideas. In the near future, it can be foreseen that studies on DNA damage and repair, and new biological targets (tissues and animal) will further corroborate the importance of these devices in radiobiology and their applications in therapy and protection.

Acknowledgments Work at the GSI microbeam is partly supported by ESA (IBER contract) and Beilstein Stiftung (NanoBic). Work at the Munich microbeam SNAKE is partly supported by the DFG Cluster of Excellence, Munich Advanced Photonics (MAP).

\section{References}

Bekker-Jensen S, Mailand N (2010) Assembly and function of DNA double-strand break repair foci in mammalian cells. DNA Repair (Amst) 9(12):1219-1228

Belyakov OV, Mitchell SA, Parikh D, Randers-Pehrson G, Marino SA, Amundson SA, Geard CR, Brenner DJ (2005) Biological effects in unirradiated human tissue induced by radiation damage up to $1 \mathrm{~mm}$ away. Proc Natl Acad Sci USA 102(40):1420314208

Bertucci A, Pocock RD, Randers-Pehrson G, Brenner DJ (2009) Microbeam irradiation of the $C$. elegans nematode. J Radiat Res 50:A49-A54

Brenner DJ, Sachs RK (2003) Domestic radon risks may be dominated by bystander effects-but the risks are unlikely to be greater than we thought. Health Phys 85:103-108

Dollinger G, Bergmaier A, Hable V, Hertenberger R, Greubel C, Hauptner A, Reichart P (2009) Nanosecond pulsed proton microbeam. Nucl Instr and Meth B 267:2008-2012

Durante M (2009) Applications of particle microbeams in space radiation research. J Radiat Res 50:A55-A58

Folkard M, Schettino G, Vojnovic B, Gilchrist S, Michette AG, Pfauntsch SJ, Prise KM, Michael BD (2001) A focused ultrasoft $\mathrm{X}$-Ray microbeam for targeting cells individually with submicrometer accuracy. Radiat Res 156:796-804

Fukamoto K, Shirai K, Sakata T, Sakashita T, Funayama T, Hamada N, Wada S, Kakizaki T, Shimura S, Kobayashi Y, Kiguchi K (2007) Development of the irradiation method for the first instar silkworm larvae using locally targeted heavy-ion microbeam. J Radiat Res 48:247-253

Gerardi S (2009) Ionizing radiation microbeam facilities for radiobiological studies in Europe. J Radiat Res 50:A13-A20

Greubel C, Hable V, Drexler GA, Hauptner A, Dietzel S, Strickfaden H, Baur I, Krücken R, Cremer T, Dollinger G, Friedl AA (2008) Competition effect in DNA damage response. Radiat Environ Biophys 47:423-429

Greubel C, Assmann W, Burgdorf C, Dollinger G, Du G, Hable V, Hapfelmeier A, Hertenberger R, Kneschaurek P, Michalski D, Molls M, Reinhardt S, Röper B, Schell S, Schmid TE, Siebenwirth C, Wenzl T, Zlobinskaya O, Wilkens JJ (2011) Scanning irradiation device for mice in vivo with pulsed and continuous proton beams. Radiat Environ Biophys. doi:10.1007/ s00411-011-0365-x

Griffith LG, Swartz MA (2006) Capturing complex 3D tissue physiology in vitro. Nat Rev Mol Cell Biol 7:211-224

Hable V, Greubel C, Bergmaier A, Reichart P, Hauptner A, Krucken R, Strickfaden H, Dietzel S, Cremer T, Drexler GA, Friedl AA, Dollinger G (2009) The live cell irradiation and observation setup at SNAKE. Nucl Instr Meth B267:2090-2097

Hauptner A, Dietzel S, Drexler GA, Reichart P, Krücken R, Cremer T, Friedl AA, Dollinger G (2004) Microirradiation of cells with energetic heavy ions. Radiat Environ Biophys 42(4):237-245

Heiss M, Fischer BE, Jakob B, Fournier C, Becker G, Taucher-Scholz G (2006) Targeted irradiation of Mammalian cells using a heavy-ion microprobe. Radiat Res 165:231-239

Jakob B, Splinter J, Conrad S, Voss KO, Zink D, Durante M, Löbrich M, Taucher-Scholz G (2011) DNA double-strand breaks in heterochromatin elicit fast repair protein recruitment, histone $\mathrm{H} 2 \mathrm{AX}$ phosphorylation and relocation to euchromatin. Nucleic Acids Res. doi:10.1093/nar/gkr230

Merz F, Müller M, Taucher-Scholz G, Rödel F, Stöcker H, Schopow K, Laprell L, Dehghani F, Durante M, Bechmann I (2010) Tissue slice cultures from humans or rodents: a new tool to evaluate biological effects of heavy ions. Radiat Environ Biophys 49:457-462 
Miller RC, Randers-Pehrson G, Geard CR, Hall EJ, Brenner DJ (1999) The oncogenic transforming potential of the passage of single alpha particles through mammalian cell nuclei. Proc Natl Acad Sci USA 96:19-22

Miller JH, Chrisler WB, Wang X, Sowa MB (2011) Confocal microscopy for modeling electron microbeam irradiation of skin. Radiat Environ Biophys. doi:10.1007/s00411-011-0371-z

Mosconi M, Giesen U, Langner F, Mielke C, Dalla Rosa I, Dirks WG (2011) 53BP1 and MDC1 foci formation in HT-1080 cells for low- and high-LET microbeam irradiations. Radiat Environ Biophys. doi:10.1007/s00411-011-0366-9

Prise KM, Schettino G, Folkard M, Held KD (2005) New insights on cell death from radiation exposure. Lancet Oncol 6:520-528

Schmid TE, Dollinger G, Hauptner A, Hable V, Greubel C, Auer S, Friedl AA, Molls M, Röper B (2009) No evidence for a different RBE between pulsed and continuous $20 \mathrm{MeV}$ protons. Radiat Res 172:567-574

Schmid TE, Dollinger G, Hable V, Greubel C, Zlobinskaya O, Michalski D, Molls M, Röper B (2010) Relative biological effectiveness of pulsed and continuous $20 \mathrm{MeV}$ protons for micronucleus induction in 3D human reconstructed skin tissue. Radiother Oncol 95(1):66-72
Schmid TE, Dollinger G, Hable V, Greubel C, Zlobinskaya O, Michalski D, Auer S, Friedl AA, Schmid E, Molls M, Röper B (2011) The effectiveness of $20 \mathrm{MeV}$ protons at nanosecond pulse lengths in producing chromosome aberrations in human-hamster hybrid cells. Radiat Res 175:719-727

Sedelnikova OA, Nakamura A, Kovalchuk O, Koturbash I, Mitchell SA, Marino SA, Brenner DJ, Bonner WM (2007) DNA doublestrand breaks form in bystander cells after microbeam irradiation of three-dimensional human tissue models. Cancer Res 67(9):4295-4302

Tartier L, Spenlehauer C, Newman HC, Folkard M, Prise KM, Michael BD, Ménissier-de Murcia J, de Murcia G (2003) Local DNA damage by proton microbeam irradiation induces poly(ADP-ribose) synthesis in mammalian cells. Mutagenesis. 18(5):411-416

Wu LJ, Randers-Pehrson G, Xu A, Waldren CA, Geard CR, Yu Z, Hei TK (1999) Targeted cytoplasmic irradiation with alpha particles induces mutations in mammalian cells. Proc Natl Acad Sci USA 96:4959-4964

Zhou H, Randers-Pehrson G, Waldren CA, Vannais D, Hall EJ, Hei TK (2000) Induction of a bystander mutagenic effect of alpha particles in mammalian cells. Proc Natl Acad Sci USA 97:2099-2104 